\title{
KONTRIBUSI KEMAMPUAN BACKHAND DAN FOREHAND DRIVE KEDINDING TERHADAP KEMAMPUAN BERMAIN TENIS MEJA MAHASISWA PJKR FKIP UNIVERSITAS BENGKULU
}

\author{
Puji Lestari \\ PENJAS FKIP UNIB, e-mail: puji9176@gmail.com \\ Ari Sutisyana \\ Universitas Bengkulu \\ Defliyanto \\ Universitas Bengkulu
}

\begin{abstract}
Abstrak
Penelitian ini bertujuan untuk mengetahui berapa besar sumbangsih kemampun backhand drive terhadap kemampuan bermain, kemampuan forehand drive terhadap kemampuan bermain dan kontribusi kemampuan backhand dan forehand Drive terhadap kemampuan bermain tenis meja. Metode penelitian yang digunakan berbentuk korelasional. Populasi dalam penelitian ini adalah mahasiswa PJKR. Sampel penelitian sebanyak 40 orang diambil 10 orang tiap masing kelas. Instrument tes yang digunakan yaitu tes Backhand,Forehand drive, dan Kemampuan bermain. Teknik Pengumpulan data penelitian menggunakan tes, Teknik analisis data menggunakan Kontribusi. Penelitian dilakukan di Kampus PJKR FKIP UNIB Berdasarkan hasil penelitian diketahui Kemampuan backhand drive $\left(X_{1}\right)$ terhadap kemampuan bermain $(Y)=$ 0,42 . Kemampuan forehand drive $\left(X_{2}\right)$ terhadap kemampuan bermain $(Y)$ 0,46 dan Kemampuan backhand $\left(X_{1}\right)$ dan forehand drive $\left(X_{2}\right)$ terhadap kemampuan bermain $(Y)$ 0,46 Kontribusi Kemampuan Backhand dan Forehand drive dengan kemampuan bermain sebesar $(21,16 \%)$.
\end{abstract}

Kata kunci: Kontribusi, Mahasiswa PJKR

\begin{abstract}
This study aims to determine kemampun backhand drive on the ability to play, the ability toehand drive on the ability to play and contributing ability backhand and forehand Drive to the ability of playing table tennis. The research method used is correlational. Population in this research is student of PJKR. The sample of research is 40 people taken 10 people each class. The test instrument used is Backhand test, Forehand drive, and Ability to play. Techniques Data collection research using tests, data analysis techniques using Contribution.. Based on the results of research known Backhand drive ability $(X 1)$ to the ability to play $(Y)=0.42$. Forehand drive (X2) ability to play (Y) 0.46 and Backhand (X1) and forehand drive (X2) ability to play (Y) 0.46 Contribution Backhand and Forehand drive ability with playing capability of (21.16\%).
\end{abstract}

Keywords: Contributions, Student 


\section{PENDAHULUAN}

permainan tenis meja merupakan suatu permainan yang menggunakan meja, bola, dan bet sebagai peralatannya. Permainan diawali dengan servis yang dilakukan pemain dengan memantulkan bola ke daerah permainan sendiri, melewati net, dan menyeberangkan bola ke daerah lawan. Pemain lawan berusaha mengembalikan servis dan pukulan dari lawannya agar permainan tetap berlangsung. Untuk memperoleh angka pemain harus melakukan pukulan-pukulan terbaiknya sehingga bisa mematikan pukulan lawan. Menurut A.M Bandi Utama, Tomoliyus, dan Sridadi (2005: 5) dalam Taufiq Hidayat permainan tenis meja adalah permainan dengan menggunakan fasilitas meja beserta peralatannya serta raket dan bola sebagai alatnya. Permainan ini diawali dengan pukulan pembuka (service), yaitu bola dipantulkan di meja sendiri lalu melewati atas net dan memantul di meja lawan, kemudian bola tersebut dipukul melalui net harus memantul ke meja lawan sampai lawan tidak dapat mengembalikan dengan baik. Pemain berusaha untuk mematikan pukulan lawan agar memperoleh angka dari pukulannya. Permainan tenis meja dapat di mainkan baik orang tua, remaja maupun anak-anak. Sarana seperti raket, bola, net dan meja sebagai tempat bermain juga tidaklah membutuhkan biaya yang tinggi. Berdasarkan penelitian yang sudah dilakukan pada bulan maret bahwa Pada umumunya mahasiswa PJKR telah mengetahui dan memahami permainan Tenis Meja walaupun belum mengetahui dan memahami secara mendalam. Mahasiswa melakukan permain tenis meja dengan menghadapi lawan-lawan bermain yang memiliki karakteristik dan jenisjenis pukulan yang beragam dan bervariasi.
Sehingga pukulan-pukulan yang mereka lakukan dapat dilakukan dengan baik dan benar, setelah dilakukannya tes kemampuan backhand dan forehand drive terhadap kemampuan bermain dapat dilihat hasil dari kemampuan bermain tenis meja mahasiswa PJKR. Seorang pemain yang bertahan akan melakukan pukulan forehand dan backhand untuk menerapkan permainan, fungsi forehand dan backhand drive sangat penting dikuasai secara mantap oleh pemain, hal ini sudah sebagian diterapkan oleh mahasiswa PJKR.

Rumusan masalah yaitu : Berapa besar kontribusi backhand dan forehand Drive dengan kemampuan bermain tenis meja mahasiswa PJKR FKIP Universitas Bengkulu? Pukulan forehand merupakan pukulan yang paling umum dilakukan dalam tenis meja. Menurut Sutarmin (2007: 21) pukulan forehand adalah pukulan bola dengan posisi telapak tangan yang memegang raket/bet menghadap ke depan. Menurut Larry Hodges (1996: 35) backhand adalah pukulan yang dilakukan dengan menggerakkan bet ke arah kiri siku bagi pemain yang menggunakan tangan kanan dan kebalikannya bagi pemain yang menggunakan tangan kiri. Pendapat tersebut menunjukkan bahwa pukulan backhand tenis meja merupakan pukulan yang digunakan untuk menyerang dari sisi backhand dengan posisi punggung tangan yang memegang raket/bet menghadap kedepan. Pukulan backhand adalah pukulan bola dengan posisi telapak tangan yang memegang bet atau raket menghadap kebelakang, atau posisi punggung tangan yang memegang bet atau raket menghadap kedepan. pemain harus menguasai teknik dasar permainan tenis meja karena hal tersebut merupakan pondamen dari teknik pertandingan tenis meja. Pemain tenis meja 
tingkat pemula agar mampu menguasai teknik dasar dengan baik maka perlu menguasai pukulan forehand dan pukulan backhand. Dijelaskan pula oleh Sumarno, dkk (2003: 23) bahwa seorang pemain harus dapat mengontrol teknik permainannya sendiri dan mengembangkannya untuk itu perlu adanya pembinaan pukulan-pukulan yang benar dimana hal ini merupakan dasar untuk meningkatkan mutu permainan.

\section{METODE PENELITIAN}

Jenis penelitian ini adalah penelitian kuantitatif yang berbentuk korelasional. Tempat penelitian ini dilakukan di lapangan Tenis Meja Kampus PJKR FKIP Universitas Bengkulu. Penelitian ini dilaksanakan pada Bulan Februari sampai dengan Maret 2017.sebagai sample dalam penelitian ini adalah 40 orang, di ambil dari masing-masing kelas 10 orang sebagai perwakilan untuk di tes kemampuan bermain Tenis Meja. Instument penelitian, sebelum digunakan untuk mengumpulan data terlebih dahulu dicobakan / try out. Dan data instrument yang digunakan memiliki angka validitas sebesar 0,67 untuk tes kemampuan drive backhand ,dan untuk tes kemampuan forehand sebesar 0,88 . memiliki angka reliabilitas sebesar 0,65 untuk tes kemampuan drive backhand ,dan untuk tes kemampuan forehand sebesar 0,96. Teknik analisis data yang digunakan dalam penelitian ini pertama dilakukan uji normalitas data, kemudian dilakukan uji homogenitas varians lalu korelasi yaitu untuk mengetahui kemampuan backhand dan forehand drive terhadap kemampuan bermain tenis meja, menggunakan rumus korelasi. kemudian dilakukan uji korelasi berganda, untuk mengetahui berapa besar kontribusi kemampuan backhand dan forehand drive terhadap kemampuan bermain tenis meja mahasiswa PJKR FKIP UNIB. Ditentukan dengan rumus: $K=r^{2} \times 100 \%$

\section{HASIL DAN PEMBAHASAN}

\section{Hasil}

1. Terdapat hubungan yang positif antara Kemampuan backhand drive terhadap kemampuan bermain pada mahasiswa PJKR FKIP UNIB. Hal ini dibuktikan dengan $R_{\text {hitung }}=0,42>R_{\text {tabel }}=0,312$, dengan taraf signifikansi $\alpha=0,05$. Artinya bahwa semakin baik kemampuan backhand drive maka semakin baik pula kemampuan bermain.

2. Terdapat hubungan yang positif antara Kemampuan forehand drive terhadap kemampuan bermain pada mahasiswa PJKR FKIP UNIB. Hal ini dibuktikan dengan $R_{\text {hitung }}=0,46>R_{\text {tabel }}=0,312$, dengan taraf signifikansi $\alpha=0,05$. Artinya bahwa semakin baik kemampuan forehand drive maka semakin baik pula kemampuan bermain.

3. Terdapat hubungan yang positif antara Kemampuan backhand dan forehand drive terhadap kemampuan bermain pada mahasiswa PJKR FKIP UNIB. Hal ini dibuktikan dengan $R_{\text {hitung }}=0,46>R_{\text {tabel }}=$ 0,312 , dengan taraf signifikansi $\alpha=0,05$. Artinya bahwa semakin baik kemampuan forehand drive maka semakin baik pula kemampuan bermain.

4. Terdapat Kontribusi antara kemampuan backhand dan forehand drive bersamasama terhadap kemampuan bermain pada mahasiswa PJKR FKIP UNIB. Diperolehan K $=21,16 \%$ maka dapat disimpulkan Kontribusi antara kemampuan backhand dan forehand drive bersama-sama terhadap kemampuan bermain tenis meja adalah sebesar $21,16 \%$ sedangkan sisanya $78,84 \%$ dipengaruhi oleh faktor lainnya 
seperti faktor latihan, peralatan, usia latihan, psikologis,fisik dan psikis.

\section{PENUTUPAN}

\section{Simpulan}

berdasarkan analisis data hasil penelitian dan pembahasan yang telah dilakukan mahasiswa PJKR FKIP UNIB menjelaskan bahwa ada Kontribusi antara kemampuan backhand $\left(\mathrm{X}_{1}\right)$ dan forehand drive $\left(\mathrm{X}_{2}\right)$ bersama-sama terhadap kemampuan bermain (Y) pada mahasiswa PJKR FKIP UNIB sebesar 21,16 \%, maka dapat disimpulkan Kontribusi antara kemampuan backhand dan forehand drive bersama-sama terhadap kemampuan bermain tenis meja adalah sebesar $21,16 \%$ sedangkan sisanya $78,84 \%$ dipengaruhi oleh faktor lainnya seperti faktor latihan,peralatan, usia latihan, psikologis,fisik dan psikis.

\section{Saran}

Adapun saran-saran yang dapat penulis sampaikan melalui hasil penelitian ini adalah sebagai berikut:

1. Bagi dosen kiranya dapat menganalisa variabel-variabel lain untuk meningkatkan kemampuan Backhand dan forehand drive terhadap kemampuan bermain.

2. Bagi pelatih tenis meja agar dapat memberikan materi yang tepat kepada atlet atau mahasiswa, khususnya untuk melatih backhand dan forehand drive yang didukung oleh materi lainnya guna meningkatkan kemampuan bermain tenis meja sehingga dapat mendukung dalam mendapatkan poin dengan mudah.

3. Bagi atlet atau mahasiswa agar dapat mengembangkan kemampuan bermain tenis meja khususnya berdasarkan analisis yang telah diteliti dalam penelitian ini.
4. Bagi peneliti yang ingin melanjutkan penelitian ini agar dapat menjadikan penelitian ini sebagai bahan informasi atau referensi dan peneliti dengan populasi atau sampel yang berbeda dan dalam jumlah yang lebih.

\section{DAFTAR PUSTAKA}

Larry Hodges. (1996). Tenis Meja Tingkat Pemula. Jakarta: PT Raja Grafindo Persada.

Sutarmin. (2007). Terampil berolahraga tenis meja. Surakarta: Era Intermedia.

Sumarno,dkk. (2003). Olahraga Pilihan 1. Jakarta: Pusat Penerbitan Universitas Terbuka Depdiknas.

Tangkudung, James. (2012). Kepelatihan Olahraga Pembinaan Prestasi Olahraga. Jakarta: Cerdas jaya . ,(2016).Macam-macam Metodologi Penelitian. Jakarta: Lensa Media Pustaka Indonesia. ,(2018). Sport Psychometrics Dasar-dasar dan instrument Psikometri. Depok :Rajagrafindo persada.

Taufiq Hidayat. (2015). Kemampuan pukulan forehand dan backhand dalam permainan Tenis Meja siswa kelas $V$ Sekolah Dasar Negeri Krapyak Kecamatan Godean Kabupaten Sleman. Skripsi. Yogyakarta: FIK UNY.

Yarmani, Tono, dan Defliyanto. 2019."Penerapan Media Dinding dalam Meningkatkan Service Forehand Backhand pada Pembelajaran Tenis Meja". Jurnal Kinestetik, Vol. 3 (1). 